\title{
Against Ambiguity
}

\author{
Martin Stacey \\ Department of Computer and Information Sciences, De Montfort University, Milton Keynes \\ mstacey@dmu.ac.uk \\ Claudia Eckert \\ Engineering Design Centre, Engineering Department, University of Cambridge \\ cme26@eng.cam.ac.uk
}

\begin{abstract}
This paper argues that the widespread belief that ambiguity is beneficial in design communication stems from conceptual confusion. Communicating imprecise, uncertain and provisional ideas is a vital part of design teamwork, but what is uncertain and provisional needs to be expressed as clearly as possible. Understanding what uncertainty information designers can and should communicate, and how, is an urgent task for research. Viewing design communication as conveying permitted spaces for further designing is a useful rationalisation for understanding what designers need from their notations and computer tools, to achieve clear communication of uncertain ideas. The paper presents a typology of ways that designs can be uncertain. It discusses how sketches and other representations of designs can be both intrinsically ambiguous, and ambiguous or misleading by failing to convey information about uncertainty and provisionality, with reference to knitwear design, where communication using inadequate representations causes severe problems. It concludes that systematic use of meta-notations for conveying provisionality and uncertainty can reduce these problems.
\end{abstract}

\section{KEYWORDS}

Collaborative design, design communication, sketching, meta-notation, knowledge level, knitwear

\section{INTRODUCTION: THE MYTH OF BENEFICIAL AMBIGUITY}

The idea that ambiguity is beneficial in communicating design ideas is counterintuitive. Surely it's better for designers to tell their colleagues exactly what they mean, as clearly as possible. But the idea that ambiguous communication facilitates cooperative designing is now widely accepted and regarded as a consensus view, at least among architects and sociologically-oriented researchers in the field of computer supported cooperative work. It directly influences what kinds of computer support for cooperative designing are considered worthwhile and developed: we have encountered the view that trying to use computers to enable designers to say exactly what they mean is a discredited enterprise ${ }^{1}$. But how messages and communicative objects can be misunderstood, or read differently, has been a neglected issue in studies of collaborative design. So giving the notion of ambiguity in design communication some sceptical scrutiny is less perverse and more urgent than it might appear.

'Ambiguous' is an ambiguous word: its standard meaning is 'interpretable in two or more distinct ways'; but it is also used to mean 'vague or imprecise'. The ambiguity of 'ambiguity' causes confusion. Just as the communication of design ideas in real life suffers from a failure to understand the nature of the problem (at least in commercial knitwear design, the industry we have studied in detail), academic analyses of 'ambiguity' in design have been muddied by the conflation of different types of imprecision into an over-broad concept of 'ambiguity'. This makes some published discussions of ambiguity in design communication impossible to interpret, even when they stem from 
a sophisticated analysis of the role of uncertainty in designing (for instance, Minneman and Harrison, 1998). The aim of our paper is to support clearer thinking in studying design, as a preliminary to supporting clearer communicating in designing.

In this paper we put forward the view that clarity in design communication is - almost always desirable, and is what computer tools for cooperative design should support; but that clarity isn't the same as detailed exactness, just as ambiguity is not the opposite of detailed exactness. Clear communication is a problematic notion, in cognitive, sociological and linguistic theory as well as in design practice. But as we have seen (see sections 1.2 and 4.3) designers failing to get their ideas correctly understood has severe consequences.

We begin by examining some discussions of ambiguity, creativity and communication in design, and contrast both our own observations of the knitwear design process and our methodological approach. In section 2 we set our goal - computer support for clear communication - and discuss what design communication needs to achieve. In section 3 we unpack the different types of 'non-rigidity' conflated in the commonly used concepts of 'ambiguity' and 'imprecision'. In section 4 (drawn largely from Stacey et al., 1999) we analyse the scope for ambiguity and imprecision in the information content of sketches used to communicate design ideas, and discuss how ambiguity influences knitwear design. In section 5 we reconsider the benefits of ambiguity in communication.

\subsection{Ambiguous communication and scope for creativity}

The view that ambiguity is beneficial in design communication is related to two doctrines, both containing much truth, that are very influential in research on design and computer supported cooperative work. The first is that ambiguity facilitates creativity by enabling reinterpretation. A lot of creative design, both by individuals and by groups jointly developing designs, involves creating sketches and other external representations. Schön (1983) views this as interacting with the sketches as in a conversation: the designers see more in their sketches than they put in when they draw them, and these insights drive further designing. The extensive body of research on how architects and other designers use sketches, notably by Goldschmidt (1991, 1994, 1999) and Goel (1995), has focused on how designers reinterpret elements of their sketches (see Purcell and Gero (1998) for a review). People can readily find unintended configurations of sketch elements (Goldschmidt, 1999), but this ordinarily requires active interest in new possibilities, usually triggered by dissatisfaction with the current design (McFadzean et al., 1999), or forgetting of context. As shown by Finke's (1990) findings on how preinventive forms can facilitate creativity, using chance forms to meet design goals is often a fruitful idea generation strategy. For reinterpretation leading to creative insight, ambiguity is a benefit, regarded as important by both researchers and reflective practitioners. But the research on sketching concentrates on early creative design, usually in architecture, where designers are relatively free of constraints. Although it is significant not just for early design but for understanding human creativity, its relevance to more tightly constrained designing is limited.

The other influential doctrine is that design is inherently social. One important contribution of sociologically-oriented studies of design practice (notably Minneman, 1991; Bucciarelli, 1988, 1994; and Henderson, 1999) is highlighting just how much designing is done in meetings as a joint activity by pairs or groups. And what designers do and why is shaped by the social organisation of the environment, their roles in the social activities of designing, and their relationships to others. But concentrating on joint problem solving obscures both the importance of solitary designing activities and the significance of how individuals design.

Minneman (1991) presents a major study of design communication in engineering, which combined observations in industry with experiments on teams doing artificial tasks (see Minneman and Leifer, 1993, for a short summary). He argues that designs are created through an interactive social process of negotiation, in which "everything is up for grabs", through proposals, reactions and counterproposals. (As Minneman acknowledges, this is a broader-than-usual notion of negotiation: the participants in a design episode produce proposals and counter-proposals seeking mutual 
understanding much more often than to achieve closure on a decision.) Minneman (1991) discusses the role of "ambiguity" in design communication at some length, arguing (section 5.3.2) that "ambiguity" is an essential part of design communication. Although Minneman acknowledges the ambiguity of the term 'ambiguity', he chooses to lump imprecision, uncertainty and provisionality in with ambiguity. In consequence, while his discussion of "ambiguity" highlights the vital importance of maintaining non-fixedness in designing, it is uninformative about how different kinds of notfixedness influence the development of a shared understanding of the design and provide space for further designing. Minneman does comment that engineering designers sometimes find ambiguity (in the strong sense we insist on in this paper) useful for maintaining a wider space of possibilities for negotiation. But it is very hard to assess this. (Bucciarelli (1994) makes a similar point about ambiguous terms - see section 2.2.)

Reporting an observational study of a team design process in industry, Minneman and Harrison (1998) devote two paragraphs to "ambiguity". These make important points about design conversation, but could mean very different things depending on the meaning of the term 'ambiguity' and on exactly which types of uncertainty are being talked about.

[From section 3] The degree of ambiguity in the communications is the key to providing the "communications space" for a common understanding to develop through exploration and explication. Ambiguous communications provide an opportunity for designers to project and reflect-breathing room from rational concerns. Designers project a story onto suggestive fragments to make a whole, creating the shared understanding.

[Section 4.4] Ambiguity, in spoken language, text, sketches, gestures and silence, is an important element in the designers' repertoire. Ambiguity is artfully employed to pull off the negotiations, indicate future process, preserve design latitude, and avoid unnecessary conflict. The ambiguity arises, not only from explicit communications, but also from those things left unsaid. Particular individuals and groups will have their own views of negotiated positions. These differing perspectives are not necessarily undesired-upon discovering discrepancies, participants discover new things while reconciling their differences.

In conversation, subtle details of tone and gestural movements can convey degrees of precision, importance and commitment. Brereton et al. (1996), who also conflate ambiguity with other forms of uncertainty, analyse how this happens in an experiment in which a small group developed a conceptual design of a bicycle rack $^{2}$. In this case, the designers signalled their subjective degree of commitment to qualitative proposals for parts of the design, to be accepted or rejected as a whole. As Minneman (1991) and Brereton et al. (1996) point out, such modulation of commitment is a rhetorical technique in a process of argument and persuasion.

Design researchers with a wide variety of perspectives have recognised that coping with ambiguity is unavoidable. Stiny (2000) points out that formally, geometric forms are inherently ambiguous. Research by Minneman's colleagues at Xerox PARC on how groups of designers use different kinds of shared workspaces, by Bly (1988) and Tang (1989, 1991; Tang and Leifer, 1988), demonstrates the importance of designers using speech, gestures and sketches to explain and disambiguate each other in conversation. (Similarly, manipulating and gesturing at objects plays an important part in communication when designers are able to interact with elements of the design situation (see Harrison and Minneman, 1996).) This work examined the relationship between media and forms of expression without analysing information content or how representations and messages are understood. In these studies, the process of creating external representations such as sketches was as important for interactive team designing as the sketches and notes themselves. Neilson and Lee (1994) report the same interdependence of speech, drawing and gestures, in a study of an architect redesigning a kitchen layout in conversation with a client. They discuss how the architect's speech and drawing jointly conveyed meaning to the client, identifying different kinds of oblique relationship between 
what was said and what was drawn, and the types of background knowledge and inference the client needed to make sense of it. This forms part of a cognitively grounded analysis of the difficulties inherent in computer interpretation of design drawings even with concurrent speech input. Like Tang (1989) and Minneman (1991), Neilson and Lee found that speech and sketching were unintelligible in isolation; they also found that confusion sometimes arose because the linguistic context failed to yield an unambiguous interpretation of a corresponding graphical expression, or because there was no straightforward relationship between simultaneous linguistic and graphical expressions. Moreover (as many others have observed) correctly interpreting graphical expressions required background knowledge and understanding of drawing conventions, and sketch elements could change their meaning or become irrelevant in a later context.

This work on communication in joint designing (especially Bly, 1988, and Tang and Leifer, 1988) has been very influential in research on design tools within the computer supported cooperative work community. Rightly so, not least for highlighting the importance of managing uncertainty in design. But insufficiently differentiated and ambiguous analyses of "ambiguity" in design communication have created the belief among some that this community understands how ambiguous and imprecise representations influence design communication. (This is a fault of the researchers' reporting rather than any lack of understanding of the varieties of uncertainty.) But we have seen that ambiguity as well as uncertainty and provisionality are often problematic: saying what you mean and understanding what you need to know is not always easy. In our view how computer tools for collaborative design can cope with ambiguity, imprecision and provisionality is an important research issue. At least in some industries, the benefits of using computational representations in early, decision-making stages of design are great enough to make this a significant issue in industrial practice.

\subsection{Motivation: our study of commercial knitwear design}

Between 1992 and 1998 Claudia Eckert carried out an ethnographic study of the knitwear design process, in which she visited 25 knitwear companies in Britain, Germany and Italy, and interviewed and observed over 80 designers and technicians. One focus of the study was the communication between designers and technicians. This is often only partially successful, leading to both inefficiency and inferior products. It constitutes a major bottleneck in the design process (Eckert, 1997, 1999, 2001).

Knitwear designers communicate patterns and garment shapes to knitting machine technicians with a technical sketch comprising a short verbal description, a set of dimensions, called 'measurements', and a freehand sketch (figure 1). The measurements are often incomplete, inconsistent and inaccurate. Designers often don't have the domain knowledge to specify shapes accurately; and they find it difficult to improve their specifications because they cannot distinguish the effects of inadequacies in their specifications from changes made later for technical reasons. The sketches should clarify the specifications, but they are often excessively imprecise or ambiguous (see section 4.3). However the technicians, who do a lot of detail design in the course of creating knitting machine programs based on these specifications, tend to ignore the sketches and rely mainly on the verbal descriptions, which only give broad indications of categories (Eckert 1997, 1999, 2001; Stacey et al., 1999).

Although a variety of other factors contribute to the ineffectiveness of designer-technician communication, the essential problem in the knitwear industry is that designers do not have a fast way to express their ideas unambiguously. This is compounded by the designers and technicians not understanding the nature of their communication problems, and consequently ascribing to other causes difficulties that are really rooted in the intrinsic difficulty of expressing knitwear designs (Eckert, 1999, 2001).

We regard knitwear design as a clear example of a situation where ambiguity is both prevalent and harmful, where clear communication is needed, where it is not adequately achieved by pencil and paper methods, and where computer tools can help. Eckert $(1997,2001)$ has argued that the efficiency and effectiveness of the knitwear design process would be enhanced by tools that enable designers to 
create much more exact and reliable specifications in a cost-effective manner; and has developed a computer tool for creating complete and correct shape specifications from partial inputs (Eckert et al., 2000; Eckert \& Bez, 2000). This system has been favourably evaluated by practising designers in industry.

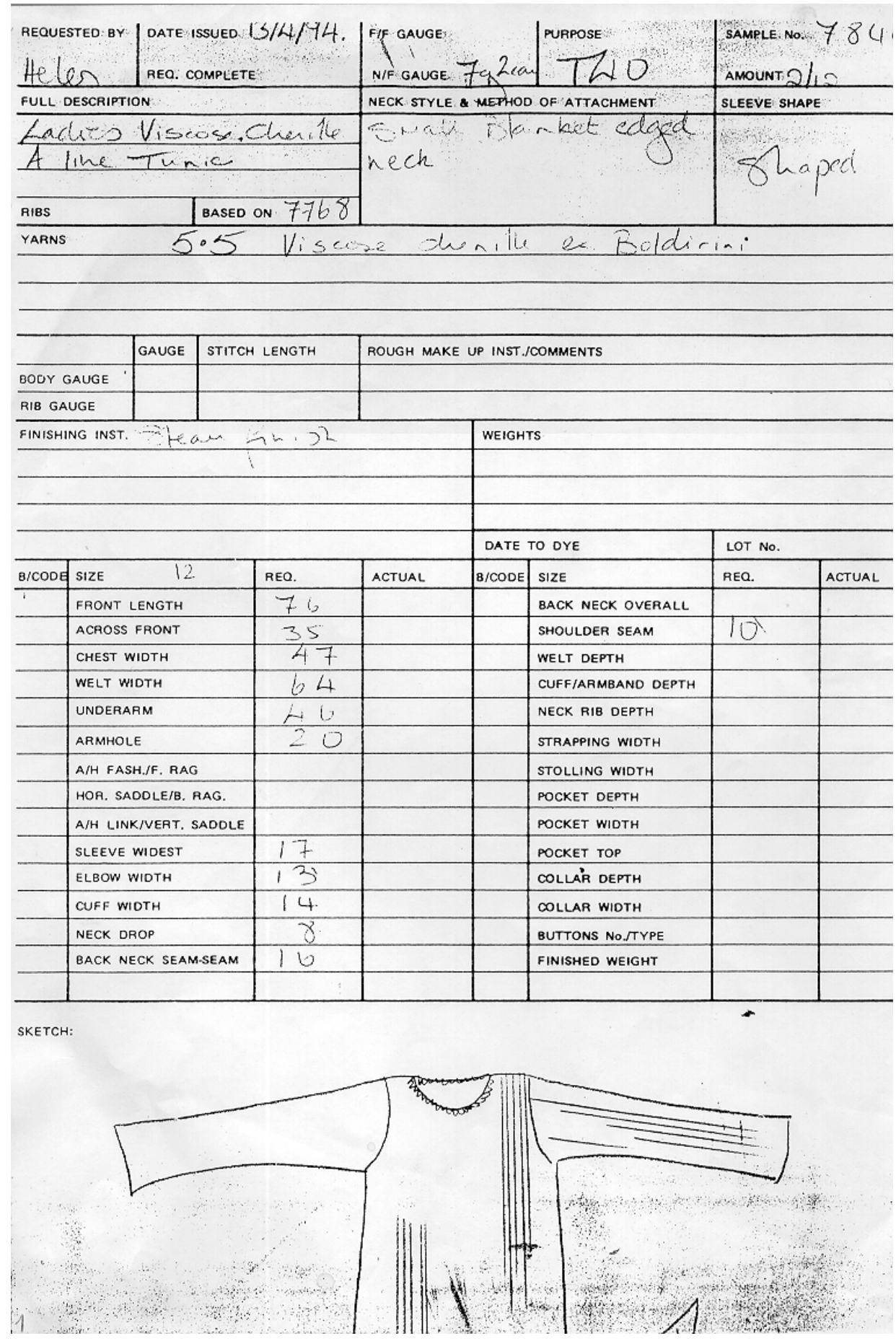

Figure 1. A knitwear designer's technical sketch

\subsection{A methodological note}

Some sociological studies of science and engineering have focused attention on the crucial role of visual representations of data and ideas in both the development and propagation of scientific and 
technological innovations, as actors in their own right in the network of participants in technical endeavours (Latour, 1987). Latour (1986) argues that since the development of perspective drawing in the Renaissance, the key to progress has been the development of new graphic representations embodying direct mappings between their perceptible form and the structure of the objects, concepts and data they depict; progress comes from identifying and focusing on the right abstractions shown in inscriptions. But the information content of any kind of inscription is relative to the reader's ability to recognise and interpret its codes. As studies of diagrammatic communication and visual literacy in design practice (notably Henderson, 1999) make clear, communication depends on both the senders' use of appropriate representations for information, and the recipients' ability to construct meaning from those representations. For instance, exact drawings from CAD models may fail to meet engineers' needs and have to be supplemented with sketches employing alternative representations, even when exactitude is in order (Henderson, 1999, ch. 3).

Surveying empirical research on how design is done, Minneman (1991, ch. 2) points out a fundamental divide between the cognitivist and sociological paradigms. Most cognitivist research has employed experiments with artificial problems, while most sociological research has relied on observations of designers working in industry. But as Minneman's (1991) research illustrates, experimental methods can be employed in the analysis of social processes; conversely, information processing analyses can be combined with ethnographic data gathering methods (Stacey and Eckert, 1999). Moreover the same data can be analysed using concepts and methods drawn from different paradigms (see Cross et al., 1996).

Design teamwork is such a complex phenomenon that any systematic analysis must concentrate on some aspects and ignore others. Research in the sociological tradition that has raised the issue of ambiguity and uncertainty in design communication has examined the social processes by which understanding is constructed and shared, but left aside the question of what understanding is created, or how individuals create and express it. Tang $(1989,1991)$ and Bly $(1988)$ focused on how designers use shared workspaces; Minneman (1991) on negotiation processes; Bucciarelli $(1988,1994)$ on the variety and complexity of engineering design activities; and Henderson (1999) on the role of visual representations and codes in structuring engineering design activities. Nevertheless Minneman and his colleagues' analyses pay much closer attention to content and the achievement of understanding than most experimental studies of design communication, which classify expressions according to broad categorisations of topic or purpose (for instance, Gabriel and Maher, 1999a,b); clarification turns up as a category (for instance, $20 \%$ of design-focused communication in Maher and Simoff's (2000) virtual design studio; 'about a third' of Olson et al.'s (1992) software design team meetings) but otherwise ambiguity and imprecision slip through the net.

Analysing information content involves taking a much more positivist view of information than that adopted by these sociologically-oriented design researchers, and using a different set of conceptual tools for constructing models. Conversely, analyses in terms of cognitive processes are valuable but are, as Smithers (1996) argues, too fine-grained and subject to individual variation to guide the design of automatic design systems and computer tools for design support. But cognitive science offers an alternative way forward, using the concept of the knowledge level, articulated by Newell (1981) and developed in knowledge engineering by the KADS group (for instance, Wielinga et al., 1992; Schreiber et al., 1993, 1999). Smithers $(1996,1998)$ argues for theories of design processes that describe designers' behaviour in terms of their knowledge and competences. This approach is becoming increasingly influential in cognitive-science-oriented research on design. Smithers (1998, 2000) and Gero and Kannengiesser (2000) have presented general knowledge level theories of the structure of designing intended to serve as frameworks for more detailed domain-specific knowledge level theories of designing. We can employ the knowledge modelling methods and tools of artificial intelligence to develop both more detailed activity-specific analyses and alternative frameworks that include communicative activities. This approach offers a way to do justice to both designers' skills and contextual understanding and the information content of representations of designs, building on the findings of both cognitive and sociological research. Developing ways to do this is one aim of our own research (Stacey and Eckert, 1999). However Neilson and Lee (1994) show not only that 
unpacking information content in design communication is possible, but that the expression and interpretation of design ideas is complex and subtle, so that formulating the information and knowledge they involve is hard.

\section{THE CHALLENGE: COMPUTER SUPPORT FOR CLEAR COMMUNICATION}

What do designers in teams need from the computer tools they use in exchanging design ideas with their colleagues? Above all, they should help the recipients of communicative acts to understand rather than misunderstand. But what, in collaborative designing, should be understood rather than misunderstood? Research on computer-mediated conversation - reciprocal communication in real time - has bypassed this question. It has rightly focused on identifying the channels through which meaning is conveyed, and how they are used in combination to transmit broad classes of information (Bly, 1988; Tang, 1989, 1991; Minneman, 1991). (However, it is naïve to assume that the media and communicative objects designers use in face to face conversation are adequate to their purpose, or that their inadequacies are recognised.) For asynchronous communication, design process tracking and knowledge management we need to go beyond the medium, to investigate the interaction between designers' information needs, their knowledge and visual literacy skills, and their communication processes. In section 2.3 we offer a way to describe what designers need to understand that makes explicit what should be conveyed (either explicitly, or implicitly in relation to context and the recipients' interpretive skills).

\subsection{Design communication scenarios}

Collaborative designing can take many forms, even within a single project, and one should be wary of generalising from conclusions reached by studying one situation. Interactions between designers can differ on at least the following dimensions:

- Time: synchronous responsive communication versus asynchronous communication

- Location of participants: co-located versus remote

- Locus of problem solving activity: joint designing versus separate individual designing

- Distribution of expertise: shared versus complementary

- Decision hierarchy: equivalent importance is attached to the tasks carried out or decisions made by the participants versus the tasks or decisions of one participant are subordinate to those of the other

- Status of participants: similar status and power versus large differences in status and power

- Formality: Informal, casual interaction versus minuted, accountable interaction

(See Eckert and Stacey, 2001, for a fuller discussion of the varieties of communication scenarios; see Kaplan et al, 1992, for a different taxonomy of tasks requiring interaction.)

Different types of interaction can require different types of computer support; conversely the media influence the mechanisms by which people use them to communicate (see Hollan and Stornetta, 1992). For instance, Bly and Minneman (1990) observed designers using the Commune shared workspace system using the ability to mark or gesture in the same place (physically impossible on paper) to signal degree of understanding, especially by contributing to and modifying others' drawings. But the medium limited the expressiveness of gestures compared with three dimensional space; for instance Neilson and Lee's (1994) architect used the third dimension in gestures to convey vertical positions on a layout diagram.

Two factors are particularly important for understanding the role and influence of imprecision and ambiguity in design communication: the extent to which the participants share context and share expertise; and the tightness of the feedback loops. As we have seen in both knitwear design and engineering, designers often communicate by reference to shared contextual information: the effectiveness of this depends on the accuracy of the senders' assumptions about the recipients' experiences (Eckert and Stacey, 2000). In face-to-face communication, failures of comprehension can be identified and corrected very quickly, and speech, gestures and sketches are used to explain and disambiguate each other (Tang, 1989, 1991; Bly, 1988; Neilson and Lee, 1994; see Minneman, 1991); 
similarly subtleties of phrasing and intonation convey degree of belief and commitment (Brereton et al., 1996). In less tightly coupled exchanges, the need to prevent rather than correct misunderstanding is correspondingly greater. In computer supported cooperative work, what are the resources available to support disambiguation? And how can the medium carry the channels through which rapid feedback and disambiguating information is conveyed? Research on computer supported cooperative designing drawing on sociological analyses of design processes has focused on getting the medium right for supporting face-to-face or remote conversations about designs (for instance, Bly and Minneman, 1990; Tang and Minneman, 1990, 1991; Ishii and Kobayashi, 1992; Scrivener et al., 1995; Wagner et al., 1999), and enhancing it with computational objects as referents for discussions (for instance, Moran et al., 1998a,b). However work in this tradition has considered asynchronous communication through recording and playback of messages produced in the same way as for computer-mediated remote conversations (Minneman and Harrison, 1998, 1999). This work has assumed that what groups of designers working remotely need is the same set of communicative resources as they have in face-to-face interaction, a view that is open to question (see Hollan and Stornetta, 1992; Kvan et al., 1997).

By contrast, knitwear design conforms to the waterfall model in nearly all companies: conceptual designs are generated by designers with no input from technicians, and handed over for further development (see Eckert, 1999, 2001). Although the technicians are usually at the same site, finding members of the other group is usually time-consuming and chancy; this is a problem in other industries, and a challenge for computer tools for collaborative design (see Bellotti and Bly, 1996). In consequence designers and technicians seldom discuss the designs in detail either at handover or later. Our experience studying knitwear design leads us to emphasise the importance of communicating through sketches and other documents. This is still important in architecture and engineering (see Henderson, 1999, chs. 3 and 4), but more often supplemented by interactive development of shared understanding. One aim of concurrent engineering approaches to engineering design is to ensure that major decisions come out of all the interested parties negotiating a shared understanding of the design that meets the concerns of all.

The less the participants discuss, and the less knowledge and contextual information they share, the more sketches, diagrams and other communications need to carry with them the means of their own interpretation. This might include labels for object types, exact shapes, explanations of what is omitted, indications of motion and change, to enable recipients to construct from more general knowledge the information that designers with the same expertise embedded in the sender's context can supply in interpreting more skeletal representations. It might also include indications of what is and is not certain and precise and important, that participants in conversations can pick up from subtleties of tone and gestural movement (Brereton et al., 1996). As memory for context evaporates over time, supplying sufficient information to enable interpretation is also important for communicating with oneself in the future.

\subsection{Boundary objects and boundary concepts}

Knitwear designers' technical sketches are classic instances of what Star (1989) terms boundary objects. These are documents and other objects that facilitate communication across the boundaries between interests and disciplines, because they can be read differently by people with different concerns and expertise, in terms of the different sets of entities, properties, relationships and principles that make up what Bucciarelli $(1988,1994)$ calls their different object worlds. (As Henderson (1999, ch. 5) points out, interpretations of boundary objects can be influenced by political agendas as well as technical knowledge and priorities.) Knitwear designers conceive designs primarily in terms of their visual and tactile properties, including their cultural associations; while technicians think in terms of the structure of the knitted fabric and the layout of structural features. As Peng (1994) points out, an important activity in multidisciplinary designing is mapping information between shared representations and discipline or activity specific representations. 
Objects such as diagrams and prototypes are not the only mediators of communication between different interest-groups and their object worlds. As Bucciarelli (1994, ch. 6) points out, technical terms are shared between communities, but their interpretations are subject to different perspectives, conventions and assumptions, so technical terms can be ambiguous when they appear clear ${ }^{3}$. Bucciarelli discusses the different meanings placed on the term 'module voltage' by the members of a team designing a photovoltaic generator: 'module voltage' functions as a boundary concept - a shared abstraction that is an abstraction from a different conceptual structure and a different set of experiences in each object world. Such alternative meanings aren't always compatible, but Bucciarelli argues that giving some space for people to work as though the term means what they think it should mean can be beneficial ${ }^{4}$. To understand design communication in detail we need to understand how boundary objects are read within object worlds.

\subsection{Design communication as constraint mapping}

How do designers communicate? Let us reformulate this question to focus on the recipient as active agent: 'how do designers understand each other?' Shared understanding, especially across object worlds, is necessarily approximate and incomplete; but nonetheless humans are remarkably effective at achieving sufficient shared understanding for their own needs.

How can we describe how designers understand messages and communicative objects encompassing all the different aspects of design situations? We require an analysis in a form that we can use to guide the development of procedures and diagrammatic conventions as well as computer support for collaborative design. Cognitive modelling of mental representations of designs is an approach that is too fine-grained and individual-specific to be tractable; while accounts in terms of the interactions between agents do not answer how questions. A fruitful analytical strategy is to interpret behaviour as rational responses to task demands. This has proved instructive at many levels of detail, whether mental processes (Anderson, 1990), problem solving actions (Simon, 1996; Newell, 1981; Anderson, 1990) or social behaviour (Garfinkel, 1967), even though the concerns and priorities driving behaviour may differ from the ostensible task (R.J. Anderson, 1994). Simon (for instance, 1996) argues that ascribing the complexities of human designing behaviour to the tasks and situations that shape this behaviour gets us further than ascribing them to the characteristics of human cognitive processes. So we adopt a rational knowledge-centred approach to understanding design processes (Stacey and Eckert, 1999).

So what do designers need to achieve when exchanging design ideas with their colleagues? The recipients of communications need to understand the implications of the new design situation for their own design activities: creating, modifying or elaborating descriptions of the artefact.

Designing is fundamentally a modelling activity (for instance, Andreasen, 1994; Peng, 1994): creating a series of information structures and physical and computational objects that describe the ultimate artefact. These models are necessarily partial; they map to and thus specify some parts or aspects of the artefacts (and other models), leaving others unspecified. As Giere (1988) argues in a discussion of the status and function of models in science, models are non-linguistic entities that have similarity relations to the aspects of reality they are models of. The role of models in designing is a little more complex: they can have similarity relations to the ultimate designed artefact, when it exists; but when the structure of the model can potentially determine the form of the artefact, the 'aboutness' of the model is a specification relationship. Complex engineering design processes involve a variety of models of different aspects of the same product, and an essential part of designing activity is using models to create either refined models or models in different forms (see Peng, 1994). These models have compatibility relations to each other: what possible artefacts if any can be jointly specified by these models ${ }^{5}$. The concepts this paper is about, 'imprecision' (flexibility in the specification), 'ambiguity' (alternative specifications), and so on, characterise the relationships between the actual models and the possible artefacts they specify (see section 3$)^{6}$. 
But the design situations that designers reason about comprise not just models of the artefact itself, but its expected environment and its purposes, functions and behaviour, as well as desires, targets, preferences, restrictions, evaluations and rationales for decisions. All these shape the spaces of possible designs that are consistent with the current design situation. Much of what is exchanged in discussions of designs - negotiation - is elements of this guiding and constraining context, and their strength and importance. Thus the recipients of design communications need to acquire or modify not just the design elements they reason with, but also their objectives, and the constraints imposed on what they can do. These implicitly define the space of possibilities within which they work, in the sense that they both provide components for moves in design space and enable moves in design space to be recognised as more or less appropriate. So the recipients of communications across discipline boundaries must map both objects and constraints between models in different object worlds. Conversely, what the senders of communications need to achieve is to supply design elements, evaluations and objectives, and impose the correct constraints on their colleagues' designing activities, to ensure that they develop shared models in appropriate ways, or that the other models they produce are consistent with the senders' own.

The recipients' ability to challenge their colleagues' choices depends on their expertise and authority, as well as on the structure of the design process. A lot of design communication is for joint designing or joint problem clarification, where proposals are open to challenge; the purpose of concurrent engineering is to ensure that all relevant interest groups and their object worlds participate in the major decisions. But in many situations the communication is between individuals or teams solving their problems independently (for instance between knitwear designers and knitting machine technicians). Here designers just want the others to do what they are asked or provide the information that is required - and in response clear explanations of why their specifications are inadequate or their ideas will not work.

Of course, creative designing is fluid and unpredictable, and is affected by factors outside rational control. Although idea generation actions are remarkably well tuned to task demands, they are influenced by prior experiences of similar objects and situations, even when the designers know they should disregard this experience - an instance of a general phenomenon known to psychologists as fixation (Jansson and Smith, 1991; Purcell and Gero, 1996). Knitwear and fashion designers actively exploit this by searching for sources of inspiration, that combined with their goals and constraints will trigger the synthesis of appropriate design ideas (Eckert, 1997). Designers' idea generation actions are influenced both by their rational understanding of what is free and what is constrained, and the degree of fixity and freedom visually implied by sketches and diagrams (see section 4), as well as how their attention is directed to different aspects of the design problem. For instance, architects' design synthesis actions are influenced by the site (Darke, 1979).

Although viewing sketches and other external representations of designs as delineations of design spaces, given form by combinations of design elements but bounded by constraints, is a rationalistic abstraction over real design thinking, it gives us useful insights into the essential role constraints play in creative design thinking. Tight constraints can be an essential spur to invention in engineering (Cross and Clayburn Cross, 1996). Finke (1990) shows that requiring experimental subjects to generate design ideas using previously imagined pre-inventive forms enhanced their creative effectiveness, and the tighter the constraints the better the design ideas. We argue elsewhere (Eckert et al., 1999) that soft constraints (to which a design should conform) play a very different role from hard constraints (to which a design must conform) in both directing design and in the learning of problem solving procedures: hard constraints foster both creative designs and the development of flexible procedures for developing innovative designs.

This perspective focuses attention on designers' information needs in interpreting messages and communicative objects in terms of their own object worlds. Considering needs is a first step to characterising information content and interpretive skills at the knowledge level in terms of procedures for constructing mappings between models. What representations, and what interpretive skills, enable correct mappings? In our view, clearly signalling the constraints on further designing 
that are implied by design actions is as important as supplying design elements to be changed, combined and reinterpreted. How can sketches, diagrams, gestures, speech, and written words and symbols both enable designers to make the right inferences about what they may and may not do, and perceptually suggest the right range of further design actions?

\section{FORMS OF UNCERTAINTY}

It is well understood that designers need to communicate skeletal or incomplete designs, in which elements or aspects are missing, or specified only qualitatively or approximately, or only in functional rather than structural terms. Moreover, they need to communicate partial designs in which design elements or decisions are provisional or are merely placeholders for more abstract categories, and in which different decisions have different importance. In conversation, phrasing and intonation can convey degrees of commitment (Brereton et al., 1996), but visual communication has no such subtle signals built in. The roughness in sketches, often the most cost-effective way to describe incomplete designs, serves to convey information about imprecision and commitment. But different types of uncertainty about the future form of the design have different implications for what designers can and cannot do. And in reading sketches it can be impossible to interpret roughness and distinguish between hints suggesting different kinds of imprecision (see section 4).

\subsection{Defining ambiguity}

The English word 'ambiguity' gets used in two very different senses. The Collins English Dictionary (1991) defines 'ambiguity' as " 1 . The possibility of interpreting an expression in two or more distinct ways. 2. Vagueness or uncertainty of meaning". The duty of a dictionary (in the English-speaking world) is to follow usage, not dictate it. But in design, the use of the second meaning, as a catch-all term for a ragbag of different types of uncertainty and inexactitude, muddles discussion of how meaning is conveyed, and should be conveyed. It conflates the need to express deferred decisions (universally accepted) with the beneficial effects of confusion (questioned at least by us). The theme of this paper is that all of these need to be understood and treated separately in analyses of design communication. One type of uncertainty, the availability of two or more qualitatively distinct interpretations, is properly termed ambiguity.

This leaves us in a quandary. What, then, can we use as a catch-all term for all the different ways an aspect of a design might not be precisely and rigidly fixed? When forced to make a choice we prefer 'uncertainty' to either 'imprecision' or 'vagueness', though 'uncertainty' emphasises degree of belief rather than quantitative uncertainty about parameter values. 'Vagueness' is best reserved for the failure (to some degree) of a representation to enable a sufficiently clear and certain interpretation.

\subsection{A typology of forms of uncertainty about incomplete designs}

Designers work with incomplete information about partially specified designs, making assumptions and provisional decisions that need to be revisited and revised. Some design processes involve conjecturing and progressively refining parameter values and other decisions (see Clarkson and Hamilton, 2000; Clarkson et al., 2000; Stacey et al., 2000). Representations of designs, whether mental or physical, are abstractions that underspecify or leave out aspects of the designed artefacts. Although forcing design communication into a rational decision-making paradigm ignores the fluid and reflexive character of the conversations through which designers develop a shared understanding and collectively evolve designs, it enables us to place a wide variety of ways in which a design might not be exact and certain into a common framework. We consider what designers need to know about how the current state of the design situation should constrain and direct further designing.

What uncertainty information engineers and other designers can, in practice, both use and pass on is a significant open research question. It is a question we are addressing in the development of computer tools to support planning and information management in complex team design activities (Stacey et al., 2000). Clarkson et al. (2000) argue from extensive experience of industrial engineering design that engineers are content with classifying values as initial estimates, feasible estimates, and final values ${ }^{7}$. 
The following concepts are conceptually distinct and potentially useful for interpreting what further moves in design space are and are not permitted by the current situation.

- Precision. How exactly the aspect of the design is specified. (Does $\mathrm{x}=10$ mean $9.998<\mathrm{x}<10.002$ or $8<\mathrm{x}<12$ ?) Less quantitatively, how far the details of the representation are meant exactly or as placeholders for qualitative values or more abstract categories. Precision is an aspect of the relationship between a model or representation and the intended space of possible designs that are compatible with it, setting the borders of that space.

- Typicality. The extent to which the aspect of the design is typical of the range of possible acceptable choices, or shows a central value in a quantitative range. (A sketch or diagram showing a relatively concrete design often represents an entire space of possible designs by showing a typical design. The interpretation of what constitutes a typical case varies between individuals.) Typicality is also an aspect of the relationship of the model or representation to its referent, concerning the location of the borders of the intended space of possible designs.

- Commitment (the opposite of provisionality). The degree to which the project is committed to keeping this aspect of the design the way it is (and conversely, how easily it can be changed to meet other needs). Representations of designs such as sketches often include elements embodying provisional decisions (or even non-decisions) to provide a context for other elements with a greater degree of commitment. Commitment/provisionality defines the mutability of the space of possible designs.

- Sensitivity. How far the aspect of the design can be changed without significantly affecting the rest of the design. (Analyses of sensitivity include the consequences of changing it more than that.) Sensitivity defines what space of possible designs is allowable given the rest of the model, rather than allowed by that aspect of the model itself.

- Input Confidence. The degree to which the inputs and assumptions on which the aspect of the design was based are stable and reliable.

- Understanding. The extent to which the user has sufficient information and expertise to decide the form of this aspect of the design from the input information. Hence, the degree to which an aspect of the design can be relied as being satisfactory in relation to the parameter values and constraints from which it was generated.

- Confidence. The degree to which an aspect of the design can be relied on as satisfactory. (The product of Input Confidence and Understanding.) Confidence defines the expected stability of the space of possible designs.

All of these concepts relate the form of the model to its creator's intentions for the design ${ }^{8}$. They are signalled (or not) in the communicative objects and messages (including gestures as well as the intonation of speech) designers use to communicate their ideas. However designers' perception and phenomenological experience of uncertainty is certainly often more wholistic and conceptually messier, for instance in the modulation of subjective degree of belief (confidence $x$ commitment?) noted by Brereton et al. (1996). Immediate perceptual understanding of precision, typicality and commitment is required for communication to drive designing forward in fruitful directions; the other forms of uncertainty information are useful for more reflective reformulation of design problems.

Failure to interpret any of these uncertainty factors correctly causes misunderstanding of the scope for further designing. Similarly, uncertainty about these factors (as well as about what the values of parameters or other choices are) causes doubt about how to proceed with a design. This is the consequence of vagueness.

All the uncertainty concepts we define here are characteristics of mappings from models to what they represent, which are constructed by interpreters from representations. However, we can view the messages and inscriptions that represent (aspects of) designs as themselves having these characteristics, for individual interpreters or communities who possess particular knowledge and skills, with which they can interpret them as (contributing to) models having relationships with these characteristics to what they are models of. Ambiguity and vagueness are characteristics of representations. Ambiguity in design communication is the availability of interpretations as 
qualitatively different alternative models, either for individuals, or for those different people with different knowledge and interpretive skills whose interpretations are relevant to the task or situation.

As is shown by our experiences of knitwear design, the generation of sketches and other forms of external descriptions that constitute accurate and unbiased representations of the generator's understanding of a design is problematic: people don't mean exactly what they draw. Idiosyncrasies and poor drawing in their sketches and diagrams bias interpretation by others towards different central meanings as well as different judgements of imprecision and provisionality (see section 4).

\subsection{Context and ambiguity}

Ambiguity is created by availability of alternative referents for words, symbols and symbolic or deictic gestures (see Neilson and Lee, 1994, for examples). What referents are available depends on the interpreter's understanding of languages and notational conventions, as well as of the design situation (see Henderson, 1999, for a discussion of the relation of notational conventions to engineering culture). But the role of prior context in design communication goes beyond the need for the recipient to recognise graphic codes and ascribe the intended referents to words and symbols. Representations of designs are abstractions from models and artefacts in which aspects of the design are not fully specified. Understanding how much of what is not shown is fixed, and what can be varied, is as essential as understanding the explicit content of a representation. Alternative interpretations of the omitted elements of a design are made possible by uncertainty or misunderstanding about the interpretive conventions to be applied to a representation, as well as the context in which it is embedded and the assumptions the generator makes about how the gaps will be filled in. Thus it can be ambiguous by omission. In other words, what is implicit in any representation depends on the interpretive skills of the recipient and the degree to which shared understanding of context has been established between the sender and the recipient.

Designers in teams need to express three aspects of a design: what - the design itself; how - by what procedure the artefact should be generated; and why - the reason why the design should be as it is. While reasons are usually apparent to the participants in joint designing activities, they can be opaque to other readers of communicative objects. Understanding the reasons for decisions is often essential for interpreting the uncertainty factors described above, as well as for interpreting omissions, in guiding further designing. Methodologies and computer systems for process management place increasing importance on recording the rationales for decisions (see Blessing, 1994), as part of managing the provision of contextual information.

\section{IMPRECISION AND AMBIGUITY IN SKETCHES}

In visuospatial design fields such as architecture, mechanical engineering, and fashion and knitwear design, sketches are a vitally important way to communicate provisional and underspecified design ideas (see Henderson, 1999). In this section, drawn largely from Stacey et al. (1999), we discuss how sketches convey information about provisional and uncertain designs, and how ambiguity and the lack of meta-notation can cause them to fail as boundary objects.

\subsection{Sketches as dense symbols}

Most fundamentally a sketch is a series of marks on paper. These marks form dense symbols, whose interpretation depends on both category information and exact spatial form (Goel, 1995). Their meanings lie in the combination of symbolic and geometric mappings from the sketch elements to the referent objects the viewer interprets the sketch to depict.

Sketch elements have symbolic meanings, defined by notational conventions and mediated by the recognition of abstract category memberships, mapping categories of mark-combinations to categories of objects or concepts. (In design conversations where category recognition is supported by spoken signals, the mapping can be very non-obvious, and can change abruptly, often by subtle implication (see Neilson and Lee, 1994). Isolated sketches need to be more straightforward.) Sketch elements may 
be abstract icons, or have shapes directly corresponding to the shapes of the object categories they represent. McFadzean et al. (1999) found that designers use a personal recurring set of graphical symbols to express abstract attributes of a design. These personal notations are based on the standard drawing conventions of the domain, but include idiosyncratic extensions and variations. Designers have recurring, idiosyncratic procedures for constructing symbols, that influence their final form. For example they would use the same curve to denote an arch, when they do not know the form of the arch.
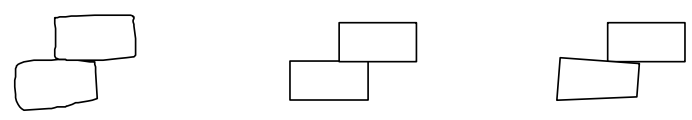

Figure 2. Sketch and its possible interpretations

Sketch elements often also have geometric meanings, mapping the exact forms of the marks and the spatial relationships between them, to the shapes and spatial relationships of the depicted objects. This geometric mapping is perceptual and non-symbolic, although interpreting pictures is to some extent a learned skill. The graphic notations for many spatial concepts embody direct mappings from their conventional shapes, so they convey geometric meaning even when only a category identifier is intended. Making geometric mappings involves recognising and exploiting drawing conventions. Recognising drawing conventions is especially important in understanding sketches of threedimensional objects. Viewers understand sketches by perceiving both the symbolic categories and the shapes of design elements - but shape perception depends on what symbols are seen. A sketch is ambiguous, as opposed to vague, when alternative ascriptions of symbols to sketch elements are possible (figure 2 shows an example).

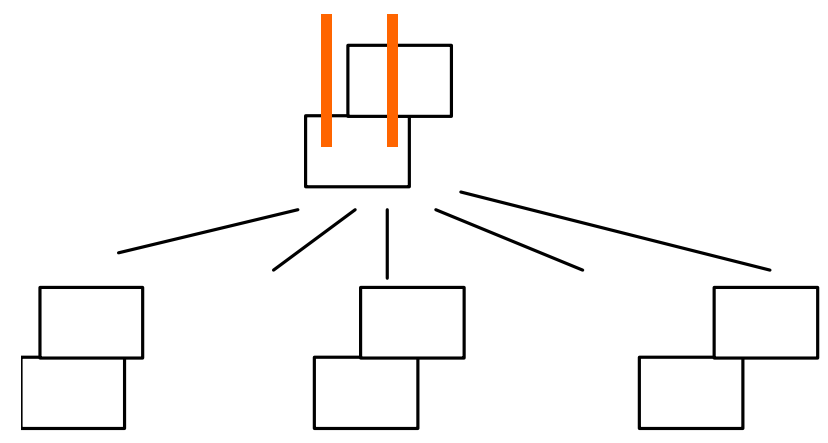

Figure 3. Sketch and its intended space of interpretations

For each viewer, a design sketch has a perceptual interpretation space: its meaning is the range of designs that it perceptually affords (see figure 3 ). Beyond this, it has a deductive interpretation space: this is the range of designs that the viewer reasons that it can cover. As sketched lines have definite shapes and sizes, they suggest proportions and magnitudes, so interpretation spaces typically have centres - the interpretation that is most strongly suggested - and fuzzy boundaries. The greater the appearance of roughness the wider and more qualitative is the perceptual interpretation space. A CAD wire frame model appears exact, so its perceptual interpretation space is very narrow, even if its deductive interpretation space is much broader for designers aware of the intent of the model. We have been told by one engineer designing with a CAD system that he can remain aware of the actual range of possibilities, so the apparent precision presents no problem. We're not sure how far we believe this, and accurate perceptual affordance of the correct interpretation space is more important in communication, where others are less aware of the intent of the model's creator. (A frequent technological approach to this problem is faking roughness in computer generated images (for instance, van Bakergem and Obata, 1991) or in computer drawing tools.) 


\subsection{Imprecision and ambiguity in sketches}

Designers typically sketch imprecise ideas, embodying tentative decisions and with purely qualitative elements, covering a space of possible designs. Such a design space is difficult to express in a pictorial form. Designers often draw a typical instance or a range of instances, which can either be typical or mark the edges of the design space that they represent. This strategy for indicating spaces can employ precise representations such as photographs of other artefacts, as well as rough sketches (Eckert and Stacey, 2000). Figure 3 might represent the relative location of two houses. Any range between the two extremes would be acceptable, but typically only the middle instance would be sketched. As design sketches are necessarily imprecise, they introduce ambiguity and inaccuracy into the transmission of meaning. Designers draw their mental models of their designs with varying degrees of accuracy according to their own conventions, but the sketches are interpreted according to the viewer's conventions as a different space of possible designs (see figure 4). Different people have different conceptions of central or typical category members; this is important when design element categories can vary over time, as in knitwear design.

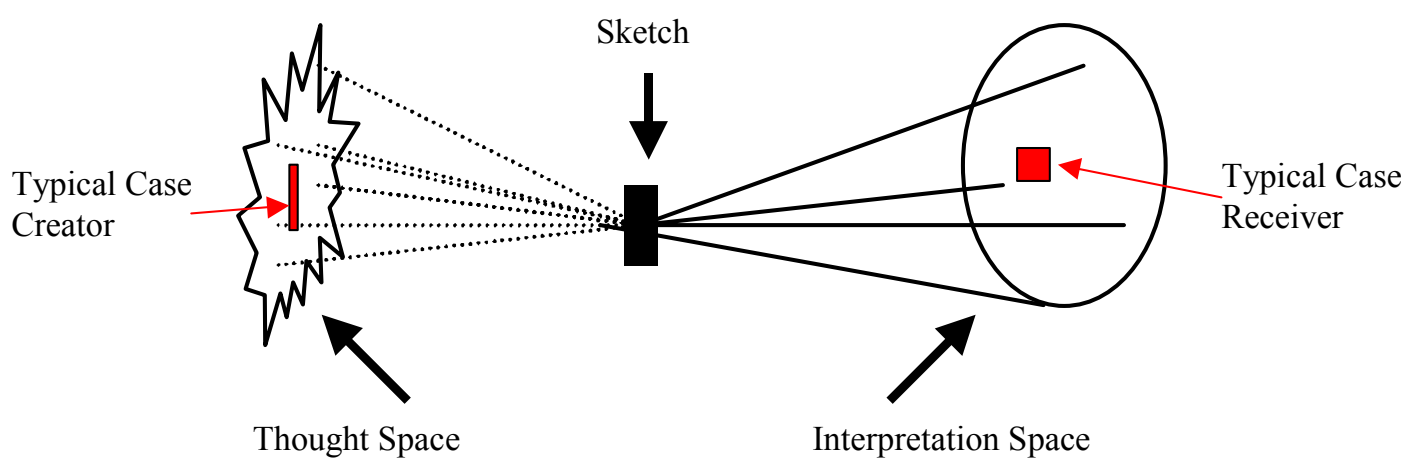

Figure 4. Thought space and interpretation space

A sketch may be ambiguous; that is, it affords alternative symbolic interpretations.

- When the sketch element can be interpreted as either of two entirely different types of design element. (Did Neilson and Lee's architect just draw a wall or part of an electrical circuit?)

- When alternative notational conventions are in conflict (a common problem in interpreting sketches of three-dimensional objects). For example, in figure 1 the parallel straight lines on the garment are intended to show the structure pattern on the garment - in this case ribs. However the lines could also stand for colour stripes. The stripes are drawn according to a context dependent drawing convention, which clashes with a convention for indicating colour stripes.

- When a sketch element can be interpreted as a roughly drawn instance of one symbol or a more precisely drawn instance of another. (Are the shapes in figure 2 rectangles? Is the left sleeve in figure 1 flared or not?)

- When a sketch element is on a fuzzy boundary between two category symbols (for instance, a slightly flared sleeve - see figure 1).

- A sketch element can be quantitatively ambiguous when it is unclear whether it is purely a category symbol or has a meaningful shape, or how wide the range of its geometric meaning should be.

- When marks can be grouped into symbols in different ways (see section 1.1).

- When the sketch is self-contradictory, so that a choice is forced between conflicting interpretations (for instance, the sweater in figure 1 is drawn with two different sleeves but is intended to be symmetrical).

In sketching (without supporting speech and gestures, or explicit use of meta-notational conventions see section 6.2) the uncertainty, provisionality and under-specification that are essential to conceptual design is only signalled by leaving elements out of the sketch (which is not always possible), or by drawing things roughly. The degree of apparent roughness is a powerful signal of how wide the 
interpretation space should be, but the recipients cannot easily distinguish between intentional roughness and poor drawing. Roughness biases interpretation (for better or worse) towards simple shapes.

\subsection{Communication through sketches in knitwear design}

Communication between knitwear designers and technicians is usually largely through sketches and written descriptions. It lacks the rapid feedback and use of words, sketches and gestures to clarify and disambiguate each other that is characteristic of conversations for joint designing (Tang, 1989, 1991; Minneman, 1991; Neilson and Lee, 1994; see Henderson, 1999), or cues for importance and provisionality in tone and gesture (Brereton et al., 1996). It often fails, largely because the available boundary objects (primarily technical sketches) do not carry the information the technicians need to constrain and direct their designing activities.

Although roughness in sketches serves to some degree to convey quantitative imprecision, it fails to communicate provisionality and commitment. One major problem we have observed in the knitwear industry (Eckert, 1997, 1999) is that the knitwear designers' technical sketches fail to convey different degrees of commitment as well as different degrees of precision. Often some elements of the technical sketches are included only to provide a context in which the important elements of the design make sense (that is, are recognised as necklines or chest patterns, or whatever). But the knitting machine technicians cannot tell the difference between important and relatively exactly specified part of their designs from unimportant details and placeholders for broad categories. Thus the technical sketches are ambiguous in that different elements may be taken seriously, treated as rough indications, or disregarded.

Both the sketches and the sets of measurements can be self-contradictory as well as inconsistent with each other: again the technicians have no way of judging what to believe, so usually take what is standard as more likely to be reliable. Communication in knitwear design also suffers from the ambiguity that results from not knowing how to interpret notational codes, especially when the sketches are intended to communicate emergent visual effects but afford (to the technicians) interpretations in structural terms.

The first result of ambiguity and insufficient precision in knitwear designers' technical sketches is that the technicians make wrong inferences about what refinements they can make to designs, in both directions. Technicians often produce prototype garments that violate the designers' intentions. Another frequent phenomenon is that technicians assert that what the designers want can't be done, are told to prove it (how can you prove a negative?), go away and produce something different with a similar visual effect, and are then suspected of lying about technical possibilities out of laziness. The further result of this is that designers and technicians mistrust each others' assertions, in particular the sketch part of the technical sketches. Technicians have told us that they rely on the written descriptions of garment categories; they largely ignore the sketches and to some extent the measurements, because they don't know what parts of them to trust or to take seriously.

Technicians also interpret both words and sketches in terms of their own past experiences of similar garments, when the meanings intended by the designers are formed by a different context, the fashion currently being created from source material shared by all designers but not by their technicians (Eckert, 1997; Eckert and Stacey, 2000). The consequence of all these misreadings and non-readings is that the end products are often more conservative than their designers intended.

\section{AMBIGUITY IN COMMUNICATION RECONSIDERED}

Viewing design communication as constraint specification helps to illuminate the role of ambiguity in different situations. It is significant that the beneficial role of ambiguity is highlighted by people either concerned with how (temporarily) solitary designers interact with their sketches, or who are interested in how groups of designers develop designs together in real-time conversations (see section 1.1). We argue in this paper that much of these benefits are due to the value (and necessity) of 
communicating provisional, qualitative, and imprecise designs (as clearly as possible), and that it is a mistake to associate provisionality and imprecision with ambiguity ${ }^{9}$. Changing others' design proposals is an essential part of designing, separately or through interactive negotiation, but this is enabled best by a clear understanding of what can and cannot be changed (without challenging earlier decisions). But ambiguity is significant: in what circumstances is ambiguity harmful, and when can ambiguity be beneficial?

Ambiguity is by definition the availability of qualitatively different interpretations; typically only one is intended. So ambiguity permits misunderstanding of the constraints the communication should place on further designing. It enables alternative views of the elements of the design, their properties and relationships, as well as of how far these can change. Ambiguity in both forms and constraints can have harmful and beneficial effects. As we describe in section 4.3, ambiguity, caused by misreading of codes, contradictions, and the absence of information about degrees of commitment, disrupts asynchronous communication between knitwear designers and technicians. Neilson and Lee (1994) also observed ambiguity disrupting face-to-face communication between architect and client. Failure to interpret constraint spaces correctly has adverse consequences when significant effort (often, all the available effort) is invested in designing outside the intended constraints.

Ambiguity can lead to the discovery of useful alternative ideas, when the sketches or other communicative objects are interpreted as a different set of objects and relationships from those intended. However we suspect that in practice this is rare in design conversations, and very much rarer than worthless misunderstandings, though ambiguous sketches a significant part of solitary designing in certain situations. Ambiguity and inadequate information about the scope for variation and development can trigger dialogue about what is and is not intended; this is likely to enhance both parties' understanding of the problem situation and the current design, in particular the constraints on further designing (note Maher and Simoff's (2000) 20\% of design communication devoted to clarification). This is most significant when the recipient sees the freedom to change something the sender has not thought to consider mutable. Thus ambiguity can be beneficial when the gain from actively clarifying shared understanding is greater than the cost of exploring unacceptable paths.

Interactively refining quick, rough and ambiguous expressions can thus be much more cost-effective than investing effort in initial clarity. But this depends on the speed and ease with which misunderstandings are corrected and boundaries explored: ambiguous boundary objects only succeed as communicative devices when the participants can recognise that incompatible readings have occurred. Even in conversation, this isn't necessarily quick. It also depends on the frequency of misunderstanding and on the participants' ability to recognise the potential for alternative readings. This, as well as the correct recognition of constraints and possibilities, depends on the extent of the participants' shared context and shared expertise, in particular how well they understand each other's representational codes.

\section{CONCLUSIONS: AGAINST AMBIGUITY}

Design is seldom solitary. Designers need to express their ideas and needs to their colleagues at many different stages of completeness and detail, often when they are uncertain and contain unresolved conflicts. The representations and codes by which they communicate are often subtly adapted to both the context and the demands of the situation. But sometimes these communication codes are inadequate to their purpose, distorting and disrupting design collaboration (see Henderson, 1999, ch. 4). Computer support for collaborative designing, especially across distances that make face-to-face conversation impossible, needs to get the medium right, to enable designers to interact and to make free use of speech and gestures as well as sketches, diagrams and more formal visual representations. This has been the focus of a lot of research on computer supported collaborative designing (see section 2.1). But where opening the right channels isn't enough, effective computer support for collaborative designing requires getting the representations right. Getting the representations right is crucial when using computer models or formal notations in conceptual design offers major benefits. 
This requires understanding the role of under-specification, uncertainty, provisionality and ambiguity in creating and communicating designs; and finding the right approach to dealing with it.

\subsection{Imprecision, constraints and decision-making}

Design is characterised by exploration and a combination of systematic and opportunistic development (see for instance Visser, 1990, 1994). Although designing can be systematically structured, designers need to make provisional decisions and suspend decisions and tasks, and think about incomplete, imprecise and sometimes self-contradictory designs. They need imprecise and qualitative mental representations and external visualisations. As Minneman (1991) points out, participants in joint design processes gain from knowing that there is scope for negotiating the final form of some aspect of the design. They can push the design ahead within an envelope of possibilities, or refine the design interactively by pushing the boundaries of what is acceptable to their colleagues. By recognising what is fixed and what is unspecified in their colleagues' communications, they gain tacit awareness of the import of these communications, the scope for change and refinement they afford. In more rationalistic terms, they gain an understanding of the constraints and requirements guiding their own design thinking, as well as the design elements they can use and modify. This is an essential part of collaborative design. But such communication of imprecise and provisional design ideas does not succeed because the descriptions, sketches, diagrams and representations that convey them are ambiguous. Rather, it succeeds because they correctly signal imprecision and provisionality (primarily through apparent roughness) to people who know how to read the codes they employ. Ambiguity can facilitate developing an understanding of the possibilities and constraints in a design situation, but only when rapid interaction between designers enables active collaborative exploration of what is meant.

As we have seen in knitwear design, communication of imprecise, provisional and under-specified design ideas often doesn't succeed. Ambiguity leads to alternative interpretations that can violate not only previous decisions but the constraints and requirements they come from. Boundary objects such as knitwear designers' technical sketches are inadequate insofar as the participants read the boundary object as suggesting constraints on what they do that are either too strong or too weak. Boundary objects fail when this misreading of possibilities and constraints leads to wrong decisions.

\subsection{Supporting imprecision and provisionality, and eliminating ambiguity}

Computer tools for designers offer the potential for clearer communication in design, though (as Henderson, 1999, illustrates) they can get in the way when they employ representations that are ineffective as boundary objects, or construction procedures that are awkward or constraining. So what can be done? In this paper we have argued that tools for computer supported collaborative design should enhance clarity about the constraints and targets that should guide further designing, and the scope of possibilities. This means that they should signal the imprecision and provisionality of design ideas, and eliminate ambiguity. But providing ways to signal imprecision and eliminate ambiguity will only help designers if they are cost-effective. As observations of designers communicating with sketches (for instance by Tang (1989), Minneman (1991) and Neilson and Lee (1994)) have shown, designers tolerate a lot of ambiguity and vagueness, for the sake of speed and not having to divert their attention from the design to how they represent it. Any enhancements to the expressiveness of communication tools and the information content of representations need to be quick and simple to use, transparent (in the sense that designers can use them while thinking about the design, not the tool or the representation), and optional. Nevertheless we regard techniques for explicitly conveying provisionality and imprecision as a potentially fruitful approach to enhancing design communication.

Sharpening human-human feedback. Rapid multimodal communication through computer tools can make communicating by disambiguating quick and rough messages and communicative objects an effective strategy for remote as well as-face to-face designing, as the successful use of computer mediated communication shows (for instance, Bly, 1988; Bly and Minneman, 1990). However, real time communication isn't always possible, video messages and records (Minneman and Harrison, 1998, 1999) may be too inefficient, and the available representations inadequate. 
Designing with computational representations. Enabling designing (rather than recording designs) by computer has proved difficult, and using CAD systems has disrupted some design processes (Henderson, 1999, ch. 4). But using computational representations of designs for creation and computation can enable designers to eliminate unwanted imprecision and ambiguity in their communications with their colleagues. This is an approach that can make communication between knitwear designers and technicians substantially more effective (Eckert et al., 2000). However communication through (inherently precise) computational representations needs to include indications of both imprecision and provisionality. How to do this is a subject for further research.

Meta-notation for provisionality and imprecison. When understanding is more reliant on unaided interpretation of sketches and diagrams, more effective communicative objects are needed. The use of simple but systematic meta-notations for degrees of provisionality, importance and precision would enhance communication in some important design processes, and potentially also human-computer communication. Computer tools should support the use of meta-notations, as well as easy annotations with words and gestures as well as static marks. Stevenson et al. (1999) propose meta-notations for quantitative imprecision in computer aided geometric design. But communicating provisionality and confidence through notation and/or annotation is an equally important issue that has so far been ignored. But to function effectively, notational conventions need to be understood by all interested parties, so using meta-notation for uncertainty and provisionality requires cultural change supported by active management as well as technology. What uncertainty information engineers and other designers can both generate and use in designing is an open research question.

\section{ACKNOWLEDGEMENTS}

Claudia Eckert's research on the knitwear design process was supported by grant GR/J40331 from the SERC/ACME, grant L12730100173 from the ESRC, and grant 717 from the Open University Research Development Fund. Her research on design processes in engineering was supported by the EPSRC rolling grant for the Cambridge University Engineering Design Centre. The authors' work has benefited from conversations about design and sketching with Jeanette McFadzean. Professor Kenneth Stacey commented helpfully on an earlier draft of this paper.

\section{REFERENCES}

Anderson, J.R. (1990): The Adaptive Character of Thought. Hillsdale, NJ: Lawrence Erlbaum Associates.

Anderson, R.J. (1994): Representations and Requirements: The Value of Ethnography in System Design. Human-Computer Interaction, vol. 8, pp. 151-182.

Andreasen, M.M. (1994): Modelling - The Language of the Designer. Journal of Engineering Design, vol. 5, pp. 103-115.

Bellotti, V.M.E. \& Bly, S.A. (1996): Walking Away from the Desktop Computer: Distributed Collaboration and Mobility in a Product Design Team. Proceedings of Computer Supported Cooperative Work '96, Cambridge, MA. New York, NY: ACM Press, pp. 209-218.

Blessing, L.T.M. (1994): A Process-Based Approach to Computer-Supported Engineering Design. $\mathrm{PhD}$ Thesis, University of Twente, Enschede, Netherlands.

Bly, S.A. (1988): A Use of Drawing Surfaces in Different Collaborative Settings. Proceedings of Computer Supported Cooperative Work '88, Portland, OR. New York, NY: ACM Press, pp. 250-256.

Bly, S.A. \& Minneman, S.M. (1990): Commune: a shared drawing surface. Proceedings of the Conference on Office Automation Systems, Boston, MA, pp. 184-192.

Brereton, M.F., Cannon, D.M., Mabogunje, A. \& Leifer, L.J. (1996): Collaboration in Design Teams: Mediating Design Progress through Social Interaction. In N.G. Cross, H.H.C.M. Christiaans \& K. Dorst (eds): Analysing Design Activity. Chichester, UK: John Wiley, pp. 319341.

Bucciarelli, L.L. (1988): An ethnographic perspective on engineering design. Design Studies, vol. 9, pp. $159-168$. 
Bucciarelli, L.L. (1994): Designing Engineers. Cambridge, MA: MIT Press.

Clarkson, P.J., Melo, A.F. \& Connor, A. (2000) Signposting for design process improvement. In J.S. Gero (ed): Artificial Intelligence in Design '00, Dordrecht, Netherlands: Kluwer Academic Publishers, pp. 333-353.

Clarkson, P.J. \& Hamilton, J.R. (2000): Knowledge modelling in aerospace design. Research in Engineering Design, vol. 12, pp. 18-38.

Collins English Dictionary (1991): Third edition, Glasgow, UK: HarperCollins.

Cross, N.G., Christiaans, H.H.C.M. \& Dorst, K., editors (1996): Analysing Design Activity. Chichester, UK: John Wiley.

Cross, N.G. \& Clayburn Cross, A. (1996): Winning by design: the methods of Gordon Murray, racing car designer. Design Studies, vol. 17, pp. 91-107.

Darke, J. (1979): The primary generator and the design process, Design Studies, vol. 1, pp. 36-44.

Dorst, K. \& Dijkhuis, J. (1995): Comparing paradigms for describing design activity. Design Studies, vol. 16, pp. 261-274.

Eckert, C.M. (1997): Intelligent Support for Knitwear Design. PhD Thesis, Department of Design and Innovation, The Open University, Milton Keynes, UK.

Eckert, C.M. (1999): Managing Effective Communication in Knitwear Design. Design Journal, vol. 2 no. 3, pp. 29-42.

Eckert, C.M. (2001): The Communication Bottleneck in Knitwear Design: Analysis and Computing Solutions. Computer Supported Cooperative Work, vol. 10, pp. 29-74.

Eckert, C.M. \& Bez, H.E. (2000): A Garment Design System Using Constrained Bézier Curves. International Journal of Clothing Science and Technology, vol. 12, pp. 134-143.

Eckert, C.M., Cross, N.G. \& Johnson, J.H. (2000): Intelligent support for communication in design teams: garment shape specifications in the knitwear industry. Design Studies, vol. 21, pp. 99112.

Eckert, C.M. \& Stacey, M.K. (2000): Sources of inspiration: a language of design. Design Studies, vol. 21, pp. 523-538.

Eckert, C.M. \& Stacey, M.K. (2001): Dimensions of Communication in Design. Proceedings of the 13th International Conference on Engineering Design, Glasgow, UK. Bury St Edmunds, UK: Professional Engineering Publishing.

Eckert, C.M., Stacey, M.K. \& Wiley, J. (1999): Expertise and Designer Burnout. Proceedings of the 12th International Conference on Engineering Design, Munich, Germany. Technical University of Munich, vol. 1, pp. 195-200.

Finke, R.A. (1990): Creative imagery: Discoveries and inventions in visualization. Hillsdale, NJ: Lawrence Erlbaum Associates.

Gabriel, G.C. \& Maher, M.L. (1999a): Coding and Modelling Communication in Architectural Collaborative Design. In O. Ataman and J. Bermudez (eds): ACADIA'99, ACADIA, pp. 152166.

Gabriel, G.C. \& Maher, M.L. (1999b): Does Computer Mediation Affect Design Representation? Pre-Proceedings of the 4th Design Thinking Research Symposium, MIT.

Garfinkel, H. (1967): Studies in Ethnomethodology. Englewood Cliffs, NJ: Prentice-Hall.

Gero, J.S. \& Kannengiesser, U. (2000): Towards a situated Function-Behaviour-Structure framework as the basis of a theory of designing. Working Paper of the Key Centre for Design Computing and Cognition, University of Sydney, Australia.

Giere, R.N. (1988): Explaining Science: A Cognitive Approach. Chicago, IL: University of Chicago Press.

Goel, V. (1995): Sketches of Thought. Cambridge, MA: MIT Press.

Goldschmidt, G. (1991): The dialectics of sketching. Creativity Research Journal, vol. 4, pp. 123143.

Goldschmidt. G. (1994): On visual design thinking: the vis kids of architecture. Design Studies, vol. 15, pp. 158-174.

Goldschmidt, G. (1999): The Backtalk of Self-Generated Sketches. In J.S. Gero \& B. Tversky (eds): Visual and Spatial Reasoning in Design, Cambridge, MA. Sydney, Australia: Key Centre of Design Computing and Cognition, University of Sydney, pp. 163-184. 
Harrison, S. R. \& Minneman. S.L. (1996): A Bike in Hand: A Study of 3-D Objects in Design. In N.G. Cross, H.H.C.M. Christiaans \& K. Dorst (eds): Analysing Design Activity. Chichester, UK: John Wiley, pp. 417-436.

Henderson, K. (1999): On Line and On Paper. Cambridge, MA: MIT Press.

Hollan, J. \& Stornetta, S. (1992): Beyond Being There. Proceedings of CHI'92, Monterey, CA. New York, NY: ACM Press, pp. 119-125.

Isaacson, W. (1992): Kissinger. London: Faber and Faber.

Ishii, H. \& Kobayashi, M. (1992): ClearBoard: A Seamless Medium for Shared Drawing and Conversation with Eye Contact. Proceedings of CHI '92, Monterey, CA. New York, NY: ACM Press, pp. 525-532.

Jansson, D.G. \& Smith, S.M. (1991): Design fixation. Design Studies, vol. 12, pp. 3-11.

Johnson-Laird, P.L. (1983): Mental Models. Cambridge, MA: Harvard University Press.

Kaplan, S.M., Tolone, W.J., Bogia, D.P. \& Bignoli, C. (1992): Flexible, Active Support for Collaborative Work with ConversationBuilder. Proceedings of Computer Supported Cooperative Work '92, Toronto, Canada. New York, NY: ACM Press, pp. 378-385.

Kuhn, T.S. (1970): The Structure of Scientific Revolutions, 2nd edition. Chicago, IL: University of Chicago Press.

Kvan, T., West, R. \& Vera, A.H. (1997): Tools and channels of communication: Dealing with the effects of computer mediation on design communiction. Proceedings of Creative Collaboration in Virtual Communities '97. Sydney, Australia: University of Sydney.

Latour, B. (1986): Visualization and Cognition: thinking with eyes and hands. Knowledge and Society: Studies in the Sociology of Culture Past and Present, vol. 6, pp. 1-40.

Latour, B. (1987): Science in Action. Milton Keynes, UK: Open University Press.

McFadzean, J. (1999): Computational Support for Conceptual Sketching: an Analysis and Interpretation of the Graphical Notation of Visual Representations. In R. Paton \& I. Neilson (eds): Visual Representations and Interpretations. Berlin: Springer-Verlag.

McFadzean, J., Cross, N.G. \& Johnson, J.H. (1999): Notation and Cognition in Conceptual Sketching. In J.S. Gero \& B. Tversky (eds): Visual and Spatial Reasoning in Design, Cambridge, MA. Sydney, Australia: Key Centre of Design Computing and Cognition, University of Sydney, pp. 163-184.

Maher, M.L. \& Simoff, S.J. (2000): Collaboratively designing within the design. In L.J. Ball (ed) Collaborative Design: Proceedings of CoDesigning 2000, Coventry University. London, UK: Springer-Verlag, pp 391-399.

Minneman, S.L. (1991): The Social Construction of a Technical Reality: Empirical Studies of Group Engineering Design Practice. PhD Thesis, Department of Mechanical Engineering, Stanford University, Stanford, CA. Xerox Palo Alto Research Center report SSL-91-22.

Minneman, S.L. \& Harrison, S.R. (1998): Negotiating Right Along: An Extended Case Study of the Social Activity of Engineering Design. In A.H.B. Duffy (ed): The Design Productivity Debate. Berlin, Germany: Springer-Verlag, pp. 32-50.

Minneman, S.L. \& Harrison, S.R. (1999): The DrawStream Station: a tool for distributed and asynchronous chats about sketches and artifacts. Proceedings of HCI'99, Munich, Germany.

Minneman, S.L. \& Leifer, L. (1993): Group Engineering Design Practice: The Social Construction of a Technical Reality. Proceedings of the 9th International Conference on Engineering Design, The Hague. Zürich, Switzerland: Heurista., pp. 301-310.

Moran, T.P., van Melle, W. and Chiu, P. (1998a): Tailorable domain objects as meeting tools for an electronic whiteboard. Proceedings of Computer Supported Cooperative Work '98, Seattle, WA. New York, NY: ACM Press, pp. 295-304.

Moran, T.P., van Melle, W. and Chiu, P. (1998b): Spatial Interpretation of Domain Objects Integrated into a Freeform Electronic Whiteboard. Proceedings of UIST 98, San Francisco, CA. New York, NY: ACM Press, pp. 175-184.

Neilson, I. \& Lee, J. (1994): Conversations with graphics: implications for the design of natural language/graphics interfaces. International Journal of Human-Computer Studies, vol. 40, pp 509-541.

Newell, A. (1981): The Knowledge Level, AI Magazine, vol. 1 no. 2, 1-20. Also published in Artificial Intelligence, vol. 18, pp. 87-127, 1982. 
Olson, G.M., Olson, J.S., Carter, M.R. \& Storrøsten, M. (1992): Small Group Design Meetings: An Analysis of Collaboration. Human-Computer Interaction, vol. 7, pp. 347-374.

Peng, C. (1994): Exploring communication in collaborative design: co-operative architectural modelling. Design Studies, vol. 15, pp. 19-44.

Purcell, A.T. \& Gero, J.S. (1996): Design and other types of fixation. Design Studies, vol. 17, pp. 363-383.

Purcell, A.T. \& Gero, J.S. (1998): Drawings and the design process. Design Studies, vol. 19, pp. 389-430.

Schön, D.A. (1983): The Reflective Practitioner: How Professionals Think in Action. New York, NY: Basic Books.

Schreiber, A. Th., Wielinga, B.J. \& Breuker, J.A. (1993): KADS: A Principled Approach to Knowledge-Based System Development. London, UK: Academic Press.

Schreiber, A. Th., Akkermans, H., Anjewierden, A., de Hoog, R., Shadbolt, N., Van de Velde, W. \& Wielinga, R. (1999): Knowledge Engineering and Management, Cambridge, MA: MIT Press.

Scrivener, S.A.R., Harris, D., Clark, S.M., Rockoff, T. \& Smyth, M. (1995): Designing at a Distance via Real-time Designer-to-Designer Interaction. In S. Greenberg, S. Hayne \& R. Rada (eds): Groupware for Real-time Drawing: A Designer Guide. London, UK: McGraw-Hill, pp. 6-23.

Simon, H.A. (1996): The Sciences of the Artificial, 3rd edition. Cambridge, MA: MIT Press.

Smithers, T. (1996): On knowledge level theories of design process. In J.S. Gero \& F. Sudweeks (eds): Artificial Intelligence in Design '96. Dordrecht, Netherlands: Kluwer Academic Publishers, pp. 561-579.

Smithers, T. (1998): Towards a knowledge level theory of design process. In J.S. Gero \& F. Sudweeks (eds): Artificial Intelligence in Design '98, Dordrecht, Netherlands: Kluwer Academic Publishers, pp. 3-21.

Smithers, T. (2000): Designing a font to test a theory. In J.S. Gero (ed): Artificial Intelligence in Design '00, Dordrecht, Netherlands: Kluwer Academic Publishers, pp. 3-22.

Stacey, M.K., Clarkson, P.J. \& Eckert, C.M. (2000): Signposting: An AI approach to supporting human decision making in design. Proceedings of the 20th Computers and Information in Engineering Conference, ASME Design Engineering Technical Conferences, Baltimore, MD. New York, NY: American Society of Mechanical Engineers.

Stacey, M.K. \& Eckert, C.M. (1999): An Ethnographic Methodology for Design Process Analysis. Proceedings of the 12th International Conference on Engineering Design, Munich, Germany. Technical University of Munich, vol. 3, pp. 1565-1570.

Stacey, M.K., Eckert, C.M. \& McFadzean, J. (1999): Sketch Interpretation in Design Communication. Proceedings of the 12th International Conference on Engineering Design, Munich, Germany. Technical University of Munich, vol. 2, pp. 923-928.

Star, S.L. (1989): The Structure of Ill-Structured Solutions: Heterogeneous Problem-Solving, Boundary Objects, and Distributed Artificial Intelligence. In L. Gasser \& M.N. Huhns (eds): Distributed Artificial Intelligence 2. Menlo Park, CA: Morgan Kaufman, p. 37-54.

Stiny, G. (2000): How to Calculate with Shapes. In E. Antonsson \& J. Cagan (eds): Formal Engineering Design Synthesis. Cambridge, UK: Cambridge University Press.

Stevenson, D.A., Duffy, A.H.B. \& Lim, S. (1999): Supporting design intent in sketching activities. Proceedings of the 12th International Conference on Engineering Design, Munich, Germany. Technical University of Munich, vol. 3, pp. 1377-1382.

Tang, J.C. (1989): Listing, Drawing, and Gesturing in Design: A Study of the Use of Shared Workspaces by Design Teams. PhD Thesis, Department of Mechanical Engineering, Stanford University, Stanford, CA. Xerox Palo Alto Research Center report SSL-89-3.

Tang, J.C. (1991): Findings from observational studies of collaborative work. International Journal of Man-Machine Studies, vol. 34, pp. 143-160.

Tang, J.C. \& Leifer, L. (1988): A Framework for Understanding the Workspace Activity of Design Teams. Proceedings of Computer Supported Cooperative Work '88, Portland, OR. New York, NY: ACM Press, pp. 226-232. 
Tang, J.C. \& Minneman, S.L. (1990): VideoDraw: A video interface for collaborative drawing. Proceedings of CHI'90, Seattle, WA. New York, NY: ACM Press, pp. 313-320.

Tang, J.C. \& Minneman, S.L. (1991): VideoWhiteboard: video shadows to support remote collaboratation. Proceedings of CHI'91, New Orleans, LA. New York, NY: ACM Press, pp. 315-322.

Van Backergem, W.D. \& Obata, G. (1991): Free Hand Plotting - Is It Live or Is It Digital? Proceedings of CAAD Futures '91, Zurich, Switzerland. Braunschweig/Wiesbaden, Germany: Vieweg \& Sohn, pp. 567-591.

Visser, W. (1990): More or less following a plan during design: opportunistic deviations in specification. International Journal of Man-Machine Studies, vol. 33, pp. 247-278.

Visser, W. (1994): The organisation of design activities: opportunistic, with hierarchical episodes. Interacting with Computers, vol. 6, pp. 235-274.

Wagner, I., Buscher, M., Morgensen P. \& Shapiro, D. (1999): Spaces for creating context and awareness - designing a collaborative virtual work space for (landscape) architects. Proceedings of HCI'99, Munich, Germany, pp. 283-287.

Wielinga, B.J. Schreiber, A.Th. \& Breuker, J.A. (1992): KADS: a modelling approach to knowledge engineering. Knowledge Acquisition, vol. 4, pp. 5-53.

\footnotetext{
${ }^{1}$ A comment made in a review of one of our papers (Eckert, 2001) - a helpful review, and not just for raising our awareness of views with which we disagree.

${ }^{2}$ A number of different researchers present a variety of analyses of this design episode, focusing on different aspects of the design process, in Cross et al. (1996).

${ }^{3}$ For instance, in the academic study of design, endless trouble is caused by the different meanings given to the term 'problem solving', especially through the misunderstanding by others of the views on the psychology of design held by Simon (for instance, 1996) and others working in the information processing paradigm.

${ }^{4}$ Trying to resolve political disputes by using terms that the warring parties could interpret in contradictory ways was a favourite tactic of Henry Kissinger (Isaacson, 1992).

${ }^{5}$ Compatibility between models may not be easy to determine. Kuhn (1970) terms scientific theories of the same phenomenon incommensurable if the terms in which they explain the phenomenon cannot straightforwardly be related. Incommensurability of theories and models of design thinking and design processes is a major problem for design research. For instance, working out the relationship between the alternative (and probably complementary rather than competitive) general knowledge level theories of designing put forward by Smithers $(1998,2000)$ and Gero and Kannengiesser $(2000)$ has not proved easy (Tim Smithers, personal communication, 2000). Comparing analyses of design based on different paradigms is extremely difficult; attempts to do so run the risk of oversimplifying one or both positions. (For instance Dorst and Dijkhuis's (1995) comparison of the views of design thinking put forward by Herbert Simon (e.g. 1996) and Donald Schön (e.g. 1983) doesn't do adequate justice to the information processing theory position.)

${ }^{6}$ In this paper we are concerned with communication through representations. The concepts of representation and model are distinct, though they share the fundamental characteristic of intensionality - 'aboutness'. Models are descriptions that are structures (physical, computational or conceptual) whose elements and relationships correspond to aspects of the form or composition or function or behaviour of the objects (or phenomena) modelled; representations are descriptions that are accessible to be apprehended and manipulated. Representations can be of models, can constitute models, and can inform the generation of mental models (see Johnson-Laird, 1983, for a discussion of mental models).

${ }^{7}$ Clarkson and colleagues have used the term 'confidence' for this; one design engineer in industry commented on this to us, that design information changed in 'maturity'.

${ }^{8}$ Precision and typicality are concepts applicable to both models and representations. Our other concepts are characteristics of aspects of models, though they must be perceived in or inferred from representations (or not, as the case may be).

${ }^{9}$ Certainly a tactical mistake, even if not a conceptual mistake. As we've seen, opinions differ on whether it's a linguistic mistake.
} 